\title{
Uphill diffusion of ultralow-energy boron implants in preamorphized silicon and silicon-on-insulator
}

\author{
M. Ferri ${ }^{\mathrm{a})}$ and S. Solmi \\ Institute of Microelectronics and Microsystems CNR-IMM, Via Gobetti, 101-40129 Bologna, Italy \\ D. Giubertoni and M. Bersani \\ Fondazione Bruno Kessler-irst, Via Sommarive, 18-Povo, Trento 38050, Italy \\ J. J. Hamilton, M. Kah, and K. Kirkby \\ Ion Beam Centre, Advanced Technology Institute, University of Surrey, Guildford, Surrey, \\ GU2 7XH, United Kingdom \\ E. J. H. Collart \\ Parametric and Conductive Implant Division, Applied Materials UK, Ltd., Foundry Lane, Horsham, \\ West Sussex, RH13 5PX, United Kingdom
}

N. E.B. Cowern

INSAT, Newcastle University, NE1 7RU, United Kingdom

(Received 3 May 2007; accepted 24 September 2007; published online 19 November 2007)

Redistribution during annealing of low-energy boron (B) implants in silicon on insulator (SOI) structures and in bulk Si has been investigated by comparing secondary ion mass spectrometry (SIMS) and simulated profiles. All the samples have been preamorphized with Ge at different implantation energies in order to investigate the effects of the position of the damage on B diffusion. Different $\mathrm{B}$ doses in the range between $2 \times 10^{13}$ and $2 \times 10^{15} \mathrm{~cm}^{-2}$ and annealing temperatures between 700 and $1100{ }^{\circ} \mathrm{C}$ have been investigated. All SIMS profiles show a B pileup in the first few nanometers of the Si matrix in proximity of the Si surface. The results of our simulations, performed on samples implanted at different doses (below and above the solid solubility), indicate that the B redistribution upon annealing can be explained with a simple model which considers the presence of traps in the surface region, without considering any asymmetric behavior of the dopant diffusion. The sink region is a few monolayers $(1-2 \mathrm{~nm})$ for doses of $2 \times 10^{13}$ and $2 \times 10^{14} \mathrm{~cm}^{-2}$, and it extends to about $7 \mathrm{~nm}$ for the highest dose of $2 \times 10^{15} \mathrm{~cm}^{-3}$, in the region of very high $\mathrm{B}$ concentration where precipitates and clusters shrink the incoming B atoms. For the two lowest B doses, the amount of $\mathrm{B}$ trapped at the surface is maximum at temperatures around $800{ }^{\circ} \mathrm{C}$, when more than $80 \%$ of the implanted dopant is made immobile and electrically inactive. In our experimental conditions, i.e., preamorphization performed with constant dose and different implantation energies, the amount of trapped B increases with reducing the depth of the amorphous layer and it is higher in the bulk Si than in SOI. (C) 2007 American Institute of Physics.

[DOI: $10.1063 / 1.2812676$ ]

\section{INTRODUCTION}

Scaling of electronic devices requires both the reduction of all the physical dimensions, including junction depth profile, and high levels of active dopant concentration. Highly active, shallow, and steep doping profile can be obtained by using preamorphized implants prior to dopant implantation and annealing at low temperature, exploiting the solid phase epitaxial regrowth (SPER) process. ${ }^{1}$ It is well known that, as a consequence of the amorphized implant, an excess of $\mathrm{Si}$ interstitials forms just beyond the amorphous/crystalline interface in the end-of-range (EOR) region. During subsequent annealing these defects evolve through the formation/ dissolution of aggregates and the release of free self-interstitials. ${ }^{1-4}$ This interstitial supersaturation causes unwanted phenomena like transient-enhanced diffusion

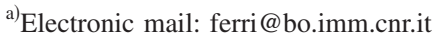

(TED), point defects clusters, and clustering between point defects and dopant with consequent electrical deactivation. ${ }^{1,2}$

A great advantage of the amorphization and SPER method is the possibility of using a low annealing temperature for a short time. Under these experimental conditions, several mechanisms such as diffusion in amorphous Si (Ref. 5) and uphill diffusion ${ }^{6-13}$ influence the dopant redistribution and activation. In particular, the surface (and the interfaces) affect the impurity profile through both the segregation and trapping of dopant atoms in energetically favorable places and acting on point defects distribution, and consequently, on the TED phenomena. These effects are particularly evident for boron ${ }^{6-9}$ and phosphorous, ${ }^{10,11}$ but have been also evidenced in ultrashallow junctions obtained by low-energy arsenic implantation. ${ }^{12,13}$

A preferential diffusion of boron at high concentrations toward the surface against the concentration gradient has been recently observed by Wang $e t ~ a l .{ }^{6}$ after ultralow-energy 
implants and low-temperature thermal cycles. Shima et al. $^{7}$ quantitatively investigated how boron segregates to regions close to the surface and concluded that the pileup is mainly confined within $0.6 \mathrm{~nm}$ of the $\mathrm{Si}$ side of the $\mathrm{SiO}_{2} / \mathrm{Si}$ interface. Duffy et al. ${ }^{8}$ reported that the effect is enhanced by the preamorphization of the substrate and it increases with decreasing depth of the amorphous layer.

The physical mechanism of the uphill diffusion is still controversial. Some authors ascribe the preferential migration toward the surface during the postimplantation annealing to the locally steep concentration gradient of interstitials. ${ }^{8,10,14}$ Alternative explanations are based on interface trapping, ${ }^{13,15}$ band bending, ${ }^{16}$ elastic stress, ${ }^{17-19}$ and segregation in front of the amorphous/crystalline interface during the solid phase epitaxial regrowth. ${ }^{20,21}$ However, besides understanding the mechanisms responsible for this anomalous behavior, knowledge of the dopant distribution in proximity of the surface and the availability of simulation codes able to predict dopant evolution during postimplantation annealing are important tools for the design and performance of modern electronic devices. At present, commercial simulators have proven inadequate for even qualitative predictions of the boron pileup phenomena at the surface/interface. ${ }^{5}$

Lately interest in silicon-on-insulator (SOI) technology has strongly increased due to the expected superior performance and fabrication advantages of this material with respect to those of bulk silicon. ${ }^{22}$ As far as the diffusion phenomenon is concerned, the presence in the SOI samples of a buried $\mathrm{Si} / \mathrm{SiO}_{2}$ interface provides another efficient sink for the interstitials besides the silicon surface. This second sink modifies the distribution of point defects during annealing and consequently, the unwanted effects related to these defects. $^{23}$ The advantages of the use of SOI with respect to bulk samples regarding electrical activation and TED reduction have been explored in recent papers. ${ }^{24-26}$

The purpose of this work is to investigate the uphill diffusion in ultrashallow $p^{+} / n$ junctions obtained by low-energy boron (B) implantation in both bulk $\mathrm{Si}$ and SOI material. In particular, the dependence of this phenomenon on the implanted dose, depth of the amorphous layer, and annealing conditions has been analyzed with the support of a simulation program which takes into account dopant trapping at the surface and allows a satisfactory prediction of the dopant redistribution upon annealing. It is interesting that due to the low energy of the B implantation, most of the dopant before annealing is located at a distance from the surface of the order of the mean projected path length, $\lambda$, i.e., the average distance of migration of the moving species (dopant-defect pair) before its dissociation. ${ }^{27}$

\section{EXPERIMENTAL}

The experiments were performed on (100)-oriented, $n$-type Czochralski (CZ) silicon wafers with resistivity 10 $-25 \Omega \mathrm{cm}$, and on SOI wafers with 55 -nm-thick, $p$-type $\mathrm{Si}$ overlayers obtained by wafer bonding technology $\left(\right.$ SOITEC $\left.^{\circledR}\right)$. Ge preamorphizing implants (PAIs) were used to produce amorphous layers of different depths. The samples were implanted to a dose of $1 \times 10^{15} \mathrm{~cm}^{-2}$ at ener- gies of 8,20 , and $25 \mathrm{keV}$ in order to amorphize the silicon to depths of about, 20,40 , and $45 \mathrm{~nm}$, respectively. ${ }^{28}$ The specimens were subsequently $\mathrm{B}$ implanted at $500 \mathrm{eV}$ to doses of $2 \times 10^{13}, 2 \times 10^{14}$, and $2 \times 10^{15} \mathrm{~cm}^{-2}$. Thermal treatments were performed using a Process Products Corporation 18lamp rapid thermal processing (RTP) annealer in nitrogen atmosphere at temperatures between 700 and $1100{ }^{\circ} \mathrm{C}$ for different times between $5 \mathrm{~s}$ and $4 \mathrm{~h}$. Care was taken in order to have the same annealing temperature both in SOI and bulk Si during annealing performed with a lamp heating system. To monitor the temperature in the annealer, we used a $k$-type thermocouple attached to the bottom of a 5-in. Si support wafer and the samples to be annealed were placed on top of this support wafer. From the comparison of the regrowth rate of the amorphous layer we found that the bulk Si samples experienced about $3{ }^{\circ} \mathrm{C}$ higher temperature than the SOI specimens. This is within the uncertainties of the techniques used.

Secondary ion mass spectroscopy (SIMS) depth profiles were performed using a CAMECA Sc-Ultra mass spectrometer. An oblique incidence $\left(68^{\circ}\right) 500 \mathrm{eV} \mathrm{O} \mathrm{O}_{2}^{+}$primary beam was used and positive secondary ions were collected. A controlled oxygen leak was introduced in the analysis chamber and the sample underwent a rotation during sputtering in order to obtain a suitable depth resolution and sensitivity. ${ }^{29}$ However, it is known that SIMS measurements could be affected by artifacts in proximity of the surface. This can cause some inaccuracies to the depth scale and concentration calibration in the first couple of nanometers. ${ }^{30}$

\section{RESULTS AND DISCUSSION}

\section{A. Simulation model of the B diffusion}

At present the commercial codes for process simulation do not take into account the phenomenon of the dopant pileup toward the surface. This gives rise to a relevant overestimation of the junction depth in the cases of very shallow implants. ${ }^{13}$ In this work the simulations of the diffused profiles are performed by using a pair-diffusion model which considers unpaired point defects and dopant-defect pairs as mobile species and the unpaired dopant on lattice sites as immobile species. A dopant atom cannot diffuse on its own, but it needs the presence of a point defect (silicon selfinterstitials in different charge states for the case of B) in the near neighborhood as a diffusion vehicle. The electrochemical potential of the pairs is the driving force for the pair flux.

High-dose Ge implantation causes the amorphization of the implanted region and an excess of $\mathrm{Si}$ interstitials just beyond the amorphous/crystalline interface in the EOR region. During subsequent annealing processes the amorphous layer epitaxially recrystallizes very quickly, while the EOR defects aggregate to form first small interstitial clusters, then $\langle 311\rangle$ complexes and dislocation loops. ${ }^{2-4}$ The recrystallization of the amorphized regions is assumed to occur instantaneously, and the as-implanted distribution, as measured by SIMS, is used as initial profile in the simulations. The implantation damage is represented by an interstitial distribution located immediately beyond the amorphous layer. The interstitials above the solubility value at the annealing tem- 
perature are considered in the form of clusters. Cluster formation is assumed to occur before the start of the diffusion simulation. Interstitial release from the clusters exponentially increases with annealing temperature. The effects of cluster dimension, which actually increases during annealing for the Ostwald ripening mechanism, ${ }^{3,4}$ as well as the effects of B segregation on the EOR, ${ }^{31}$ were not taken into account. The surfaces are considered sinks for the interstitials, i.e., the interstitial concentration at the surfaces is kept constant at the equilibrium value of the annealing temperature.

To take into account the B uphill diffusion toward the surface, we introduce a "trap" distribution into the $\mathrm{Si}$ in the first 2-3 nm below the Si/gas interface. This simple approach allows us to strongly improve the agreements between simulation and measured profiles in a wide range of experimental conditions. The following reaction term has been implemented:

$$
B I+T \underset{k_{b}}{\stackrel{k_{f}}{\rightleftarrows}} B T+I,
$$

where the traps $T$, as well as the complexes $B T$, are immobile during the diffusion process. The time evolution of such complexes can be written as follows, taking into account the mass action law,

$$
\frac{\partial C_{B T}}{\partial t}=k_{f}\left[C_{B I} C_{T}-K_{\mathrm{eq}}^{-1} C_{B T}\right],
$$

where $K_{\mathrm{eq}}=k_{f} / k_{b}$ represents the equilibrium constant of the reaction.

All the simulations are performed with an equilibrium constant reaction $K_{\text {eq }}$, which favors a rapid formation of the $B T$ complexes, and with the trap density used as a fitting parameter. For SOI samples traps are also introduced in the buried $\mathrm{Si} / \mathrm{SiO}_{2}$ interface. Furthermore, for short lowtemperature annealings, when the EOR defects were not completely removed, traps were also associated to these defects. For all the other parameters, we refer to the default values used in Ref. 32.

\section{B. Comparison with the experimental profiles}

Figure 1 shows the comparison between simulated and SIMS profiles of Ge PAI samples at $20 \mathrm{keV}$ and B-implanted at $2 \times 10^{13} \mathrm{~cm}^{-2}$ after annealing for $60 \mathrm{~s}$ at various temperatures both in SOI [Fig. 1(a)] and in bulk material [Fig. 1(b)]. The graphs clearly evidence the B diffusion toward the surface and the consequent pileup in the surface region. The simulations are in excellent agreement with the experimental profiles at high annealing temperatures, while some differences in the shape of the B distribution are present at the lowest temperature. However, the phenomenon of the uphill diffusion is accurately described, and the amount of B collected on the surface region is correctly evaluated. This demonstrates that the evolution of the B distribution, apparently against the concentration gradient, is consistent with a Fickian redistribution; in fact, the good simulation of the SIMS profiles is just obtained by introducing trapping sites in proximity of the surface, without considering any asymmetric behavior of the dopant movement. The presence of unsatur-

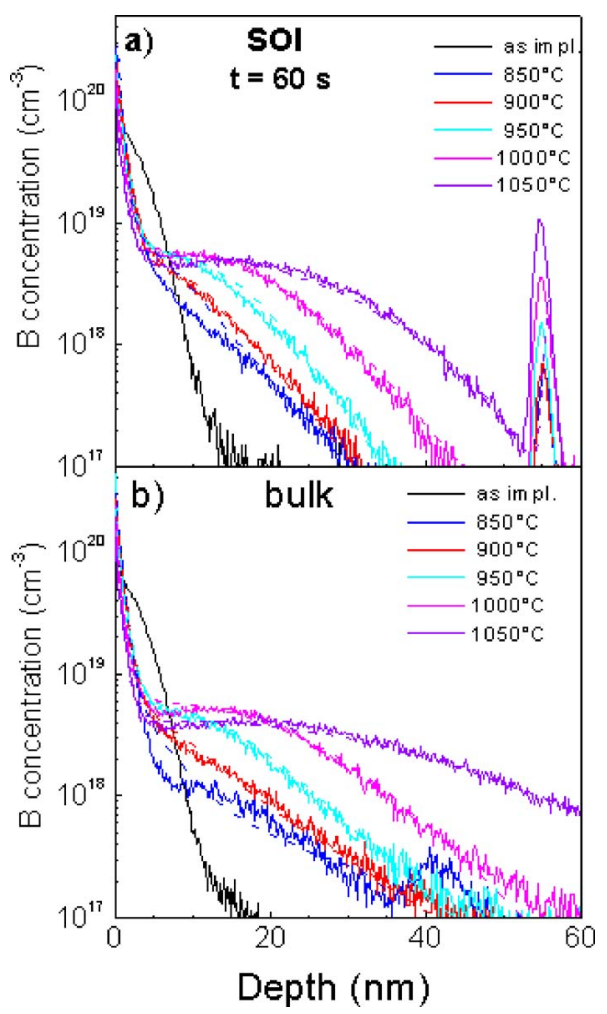

FIG. 1. (Color online) Comparison between simulated (dashed lines) and SIMS profiles (continuous lines) of PAI samples at $20 \mathrm{keV}$, B implanted with dose $2 \times 10^{13} \mathrm{~cm}^{-2}$ after isochronal annealing of $60 \mathrm{~s}$ at various temperatures in SOI (a), and in bulk material (b). The graphs clearly evidence the $\mathrm{B}$ diffusion toward the surface and the consequent pileup in the surface region.

ated traps in the surface region drives the $[\mathrm{BI}]$ pair concentration to be very small, and thus creates a huge gradient between the B profile and the traps region. This gradient, not visible by SIMS but evidenced by the simulations, drives the phenomenon of uphill diffusion. On the contrary, simulations performed without the introduction of traps near the surface produce a significant overestimation of junction depth and an incorrect determination of the B concentration in the surface region (not shown).

The amount of $\mathrm{B}$ which is distributed into the $\mathrm{Si}$, i.e., the one which is not trapped at the surface, can be evaluated by the SIMS profiles and on the basis of the simulations. The obtained results are reported in Fig. 2 for the B-implanted dose of $2 \times 10^{13} \mathrm{~cm}^{-2}$ as a function of annealing temperature for a $60 \mathrm{~s}$ treatment. The data refer to the SOI samples preamorphized with Ge implantation at different energies, in order to locate the EOR defects at different depths inside the SOI layer. In all samples a minimum in the free-B amount at around $800-850^{\circ} \mathrm{C}$ is evident; at these temperatures more than $80 \%$ of the implanted B is trapped at the surface. The tendency of B to segregate on the surface traps is higher at low temperature and decreases with increasing temperature. However, at low temperatures the phenomenon is limited by the low diffusivity which does not allow the $\mathrm{B}$ atoms to reach the traps at the surface. This is confirmed by the dependence of the trapped $\mathrm{B}$ amount from the position of the EOR defects. Higher trapping is obtained in the samples where the dissolving EOR defects, which release interstitials 


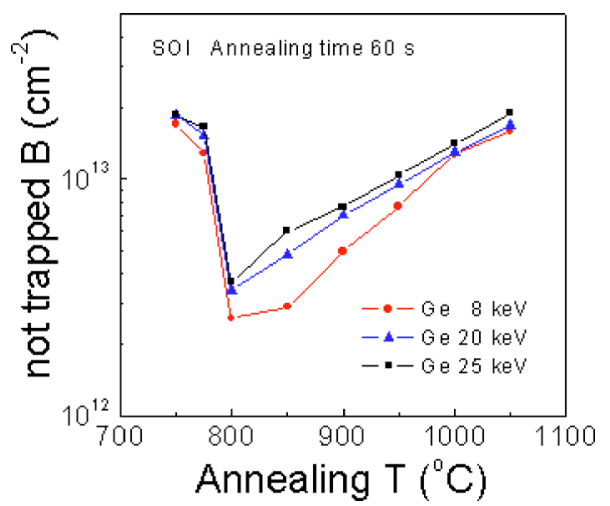

FIG. 2. (Color online) Amount of untrapped B vs annealing temperature for isochronal treatments of $60 \mathrm{~s}$ in PAI SOI samples with Ge at different energies, in order to locate the EOR defects at different depths. The B-implanted dose was $2 \times 10^{13} \mathrm{~cm}^{-2}$.

and promote $\mathrm{B}$ diffusion, are nearer to the surface. The interstitial distribution after $60 \mathrm{~s}$ annealing at $800{ }^{\circ} \mathrm{C}$ for two different depths of the EOR is reported in Fig. 3. A higher interstitial supersaturation in the surface region where the $\mathrm{B}$ is located and a stronger interstitial flux toward the surface are produced in the sample implanted with $\mathrm{Ge}$ at $8 \mathrm{keV}$. These conditions are responsible for the higher B trapping on the surface traps.

By increasing the annealing temperature, the tendency to trap B atoms is reduced. This effect, together with lowering of interstitial supersaturation with increasing temperature, allows for B atoms to avoid the surface traps and to diffuse inside the bulk in amounts which increase with increasing annealing temperature. However, only for temperatures higher than $1050{ }^{\circ} \mathrm{C}$ do we have a nearly complete release of the trapped B (see Fig. 2).

The different evolution of the interstitial supersaturation is also responsible for the differences in B trapping between the SOI and bulk Si (shown in Fig. 4) for B-implanted samples at $2 \times 10^{14} \mathrm{~cm}^{-2}$. In fact, in SOI samples the buried oxide acts as a sink for interstitials, increasing the EOR dissolution rate and reducing the enhancement of B diffusion. ${ }^{8}$

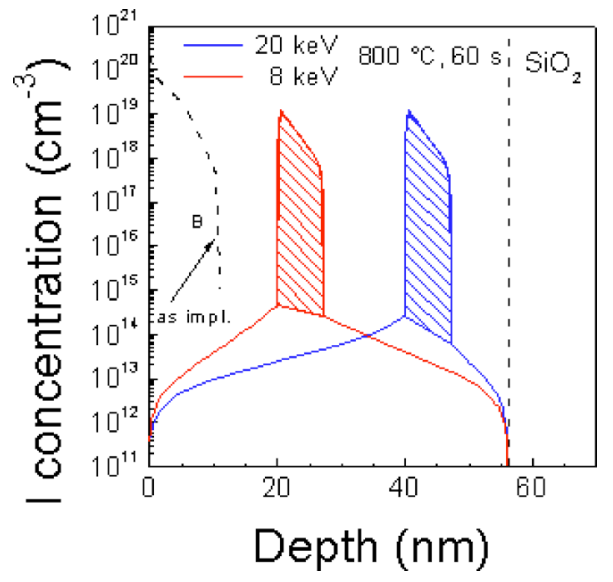

FIG. 3. (Color online) Interstitial distribution after $60 \mathrm{~s}$ annealing at $800{ }^{\circ} \mathrm{C}$ for two different depths of the EOR produced by PAI of Ge at $8 \mathrm{keV}$ (red) and $20 \mathrm{keV}$ (blue) in SOI samples. The sketched areas refer to clustered interstitials. The as-implanted B distribution for a dose of $2 \times 10^{13} \mathrm{~cm}^{-2}$ is also reported.

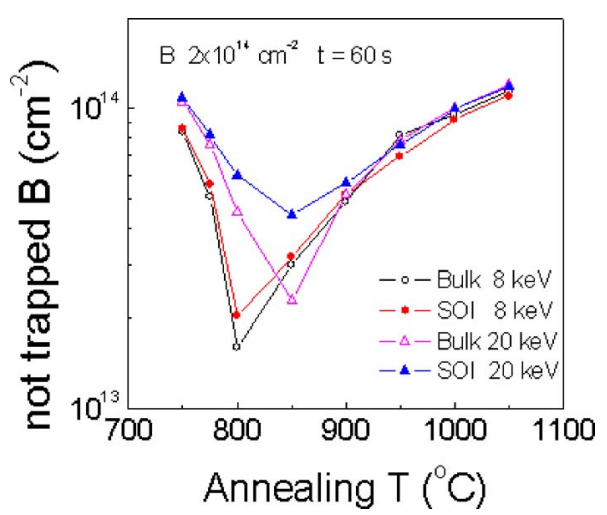

FIG. 4. (Color online) Amount of untrapped B vs annealing temperature for isochronal treatments of $60 \mathrm{~s}$ in SOI and bulk Si PAI samples with Ge at different energies. The B-implanted dose was $2 \times 10^{14} \mathrm{~cm}^{-2}$.

The effect is more evident for the samples preamorphized at $20 \mathrm{keV}$ due to the proximity of the EOR defects to the buried oxide layer. Also, for this dose the surface trapping in the samples preamorphized at $8 \mathrm{keV}$ is higher with respect to the surface trapping exhibited by the samples more deeply preamorphized at $20 \mathrm{keV}$.

The trend of the untrapped B vs temperature shown in Fig. 4 is in excellent agreement with that of the sheet resistivity reported in Ref. 33. The resistivity is strictly related to the active $\mathrm{B}$ concentration. Two effects contribute to the B deactivation: (i) B trapping in proximity of the surface and (ii) formation of neutral Boron Interstitial Clusters (BICs) inside the $\mathrm{Si}$ lattice in the regions where a high interstitial concentration meets $\mathrm{B}$ atoms ${ }^{34}$; both these contributions increase with increasing interstitial supersaturation. However, the strong correlation between resistivity and surface trapping indicates that this last effect is dominant, under these experimental conditions, in determining the resistivity of the implanted layer.

Junction depths $\left(X_{j}\right)$ evaluated from SIMS profiles at a concentration of $5 \times 10^{17} \mathrm{~cm}^{-3}$ for B-implanted samples at $2 \times 10^{13} \mathrm{~cm}^{-2}$ are reported in Fig. 5 as a function of annealing temperature. A reduction of $X_{j}$ is observed for the

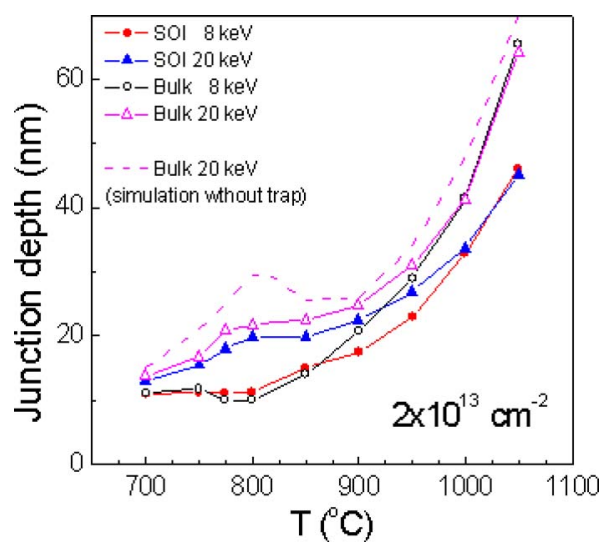

FIG. 5. (Color online) Junction depths $\left(X_{j}\right)$, evaluated from SIMS profiles at $5 \times 10^{17} \mathrm{~cm}^{-3}$ concentration, for $2 \times 10^{13} \mathrm{~cm}^{-2}$ B-implanted samples as a function of annealing temperature for $60 \mathrm{~s}$ isothermal treatments. The figure shows the results of SOI and bulk Si PAI at 8 and $20 \mathrm{keV}$. The values obtained from simulations performed without considering surface trapping are also shown (dashed line) for a bulk Si sample PAI at $20 \mathrm{keV}$. 


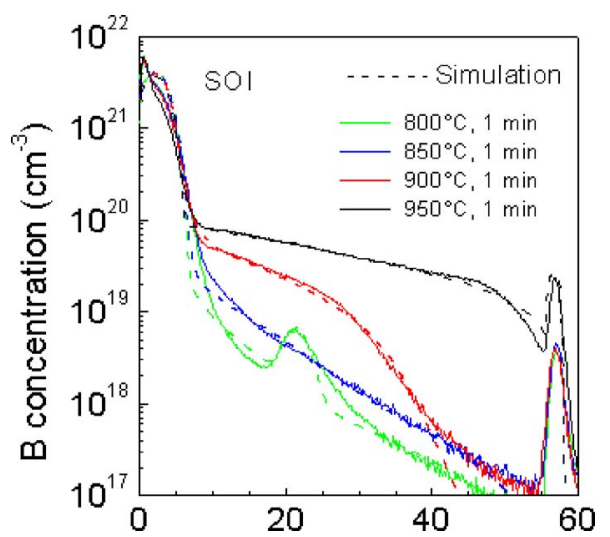

FIG. 6. (Color online) Comparison between simulated (dashed lines) and SIMS profiles (continuous lines) in SOI samples preamorphized at $8 \mathrm{keV}$ and $\mathrm{B}$ implanted at $2 \times 10^{15} \mathrm{~cm}^{-2}$ after isochronal annealing for $60 \mathrm{~s}$ at various temperatures. For the simulation at $800{ }^{\circ} \mathrm{C}$, traps at the EOR, in amounts to fit the experimental profile, were also considered in order to describe the effects of $\mathrm{B}$ segregation on these defects.

samples preamorphized at $8 \mathrm{keV}$ at temperatures where the surface trapping is higher $\left(775-850^{\circ} \mathrm{C}\right)$. This means that under these conditions the diffusion toward the traps prevails on the in-diffusion. For temperatures higher than $900{ }^{\circ} \mathrm{C}$ a shallower $X_{j}$ in SOI material with respect to bulk $\mathrm{Si}$ is obtained, in agreement with previous observations. ${ }^{26}$ This effect was attributed to the interstitial recombination on the buried oxide layer. ${ }^{25,26}$ In order to point out the role of surface trapping on junction depth, a simulation performed without taking into account this effect (dashed line) is also reported in Fig. 5. The highest difference between the simulation and the experimental data occurs at temperatures around $800{ }^{\circ} \mathrm{C}$, where the highest TED effect (for an isochronal process ${ }^{35}$ ) and surface trapping occur. It is interesting to notice the apparent paradox due to surface trapping, i.e., under particular conditions of implantation and annealing, the higher the diffusivity, the shallower the $X_{j}$ value, and the higher the sheet resistivity. Similar behavior is also obtained for $X_{j}$ of the samples B-implanted at $2 \times 10^{14} \mathrm{~cm}^{-2}$ (not reported).

The samples implanted at $2 \times 10^{15} \mathrm{~cm}^{-2}$ are characterized by a very high (around $4 \times 10^{21} \mathrm{~cm}^{-3}$ ) B concentration at the surface. Figure 6 shows the comparison between SIMS

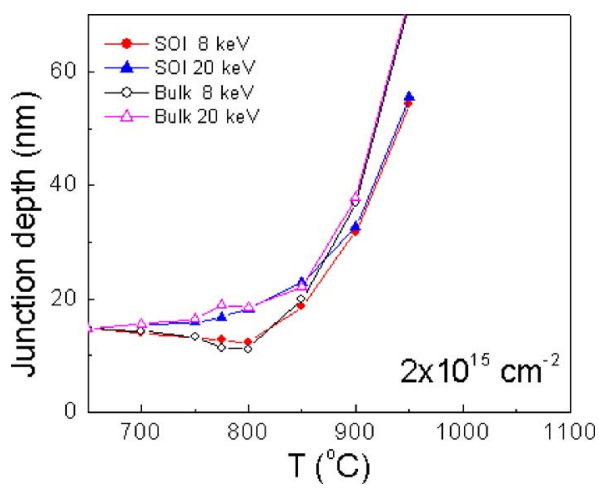

FIG. 7. (Color online) Junction depths $\left(X_{j}\right)$, evaluated from SIMS profiles at a concentration of $5 \times 10^{18} \mathrm{~cm}^{-3}$, for B-implanted samples at 2 $\times 10^{15} \mathrm{~cm}^{-2}$ as a function of annealing temperature for $60 \mathrm{~s}$ isothermal treatments. The figure shows the results of SOI and bulk Si PAI at 8 and 20 $\mathrm{keV}$.

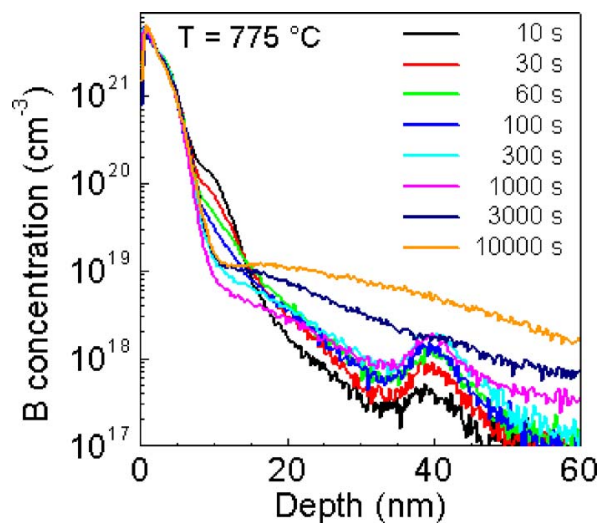

FIG. 8. (Color online) Evolution of the B distribution during annealing at $775{ }^{\circ} \mathrm{C}$ of bulk Si samples preamorphized at $20 \mathrm{keV}$ and B implanted at $2 \times 10^{15} \mathrm{~cm}^{-2}$.

and simulated profiles for SOI samples $60 \mathrm{~s}$ annealed at different temperatures. For this high dose, SIMS profiles also show a B accumulation at the surface; however, in this case the traps rapidly saturate by the large quantity of available dopant, and the amount of $\mathrm{B}$ which diffuses into the $\mathrm{Si}$ is controlled by the precipitates and clusters present in the heavily doped surface region, rather than by the trapping phenomenon at the surface. In fact, no significant difference was evidenced in the region deeper than $5 \mathrm{~nm}$ (and consequently, in $X_{j}$ ) between the simulations performed with or without traps. However, in order to obtain accurate fits in the simulations it is necessary to force the active boron concentration, which is able to form the mobile pairs, to reduce in a few seconds from the initial value $\left(\sim 2 \times 10^{20} \mathrm{~cm}^{-3}\right.$, immediately after the SPER) to the solid solubility value at the annealing temperature. In this way the entire surface region (about $7 \mathrm{~nm}$ ), rich with B precipitates and clusters, behaves as a sink for the mobile dopant and a B flux toward the surface is still obtained. This also explains the retrograde behavior of $X_{j}$ observed for this high dose at temperatures lower than $850^{\circ} \mathrm{C}$ by the PAI samples at $8 \mathrm{keV}$ both in SOI and in bulk Si (see Fig. 7).

The time evolution of the dopant distribution during annealing is clearly evidenced by the results reported in Fig. 8, which shows SIMS profiles of samples B-implanted at 2 $\times 10^{15} \mathrm{~cm}^{-2}$ and annealed at $775^{\circ} \mathrm{C}$ for different times. A shoulder at about $2 \times 10^{20} \mathrm{~cm}^{-3}$ appears after the first annealing step $(10 \mathrm{~s})$. This phenomenon, not observed in the samples Ge-implanted at $8 \mathrm{keV}$, is attributed to the B diffusion in the amorphous silicon before the recrystallization. ${ }^{4}$ The boron profile at high concentrations $\left(>2 \times 10^{20} \mathrm{~cm}^{-3}\right)$ located in the first $7 \mathrm{~nm}$ is immobile upon annealing (due to the formation of cluster or precipitates ${ }^{36}$ ). After the SPER completion, the $\mathrm{B}$ in the shoulder begins to diffuse mainly toward the surface. According to above observations (Fig. 6), simulation indicates that this can be explained assuming a gettering action of the surface traps and of the precipitates and clusters already present in the high-concentration B profile which act as sinks for the B atoms.

\section{CONCLUSION}

After annealing ultrashallow junctions obtained by lowenergy $(500 \mathrm{eV}) \mathrm{B}$ implantation in preamorphized SOI and 
in bulk Si show a strong effect of uphill diffusion which confines a relevant amount of dopant in the proximity of the surface. This redistribution can be accounted for by simulations based on pair diffusion models and with the introduction of trapping sites in proximity of the surface, without considering any asymmetric behavior of the dopant movement. The amount of trapped B increases with decreasing temperature, and, for a fixed temperature, is higher under conditions of higher diffusivity. The correlation between trapped B and diffusivity explains the increase of the trapped $B$ with reduced depth of the amorphous layer and the differences observed between SOI layers and bulk Si.

The sink region is a few monolayers $(1-2 \mathrm{~nm})$ thick for doses of $2 \times 10^{13}$ and $2 \times 10^{14} \mathrm{~cm}^{-2}$, probably due to trapping in energetically favorable places in proximity of the surface, and extends to about $7 \mathrm{~nm}$ for the highest dose of $2 \times 10^{15} \mathrm{~cm}^{-3}$, corresponding to the region of very high B concentration where precipitates and clusters shrink the incoming B atoms. For the two lowest doses, at temperatures around $800{ }^{\circ} \mathrm{C}$, more than $80 \%$ of the implanted dopant is made immobile and electrically inactive. For the highest dose of $2 \times 10^{15} \mathrm{~cm}^{-3}$ the traps are rapidly saturated by the large quantity of available dopant, and the amount of B which diffuses into the $\mathrm{Si}$ is controlled by the precipitates and clusters present in the heavily doped surface region. No significant difference was observed in the region deeper than $5 \mathrm{~nm}$, and consequently in the junction depth, between the simulations performed with or without traps.

\section{ACKNOWLEDGMENT}

This work was partially supported by the Fondi Integrativi Ricerca di Base (FIRB) national project (Contract No. RBNE012N3X).

${ }^{1}$ P. A. Stolk, J. H.-J. Gossmann, D. J. Eaglesham, D. C. Jacobson, C. S Rafferty, G. H. Gilmer, M. Jariz, and J. M. Poate, J. Appl. Phys. 81, 6031 (1997).

${ }^{2}$ M. Servidori, Z. Sourek, and S. Solmi, J. Appl. Phys. 62, 1723 (1987).

${ }^{3}$ A. Claverie, B. Colombeau, B. De Mauduit, C. Bonafos, X. Hebras, G. Ben Assayag, and F. Cristiano, Appl. Phys. A 76, 1025 (2003).

${ }^{4}$ C. Bonafos, D. Matoit, and A. Claverie, J. Appl. Phys. 83, 3008 (1998).

${ }^{5}$ S. H. Jain, P. B. Griffin, J. D. Plummer, S. Mccoy, J. Gelpey, T. Selinger, and D. F. Downey, J. Appl. Phys. 96, 7357 (2004).

${ }^{6}$ H. C.-H. Wang, C. C. Wang, C. S. Chang, T. Wang, and C. H. Diaz, IEEE Electron Device Lett. 22, 65 (2001).

${ }^{7}$ A. Shima, T. Jinbo, N. Natsuaki, J. Ushio, J.-H. Oh, K. Ono, and M. Oshima, J. Appl. Phys. 89, 3458 (2001).

${ }^{8}$ R. Duffy, V. C. Venezia, A. Heringa, T. W. T. Husken, M. J. P. Hopstaken, N. E. B. Cowern, P. B. Griffin, and C. C. Wang, Appl. Phys. Lett. 82, 3647 (2003).

${ }^{9}$ M. Y. L. Jung, R. Gunawan, R. D. Braatz, and E. G. Seebauer, J. Appl. Phys. 95, 1134 (2004).
${ }^{10}$ R. Duffy, V. C. Venezia, J. Loo, M. J. P. Hopstaken, M. A. Verheijen, J. G. M. van Berkum, G. C. J. Maas, and C. Demeurisse, Appl. Phys. Lett. 86, 081917 (2005)

${ }^{11}$ S. Ruffell, I. V. Mitchell, and P. J. Simpson, J. Appl. Phys. 97, 123518 (2005).

${ }^{12}$ S. Solmi, M. Ferri, M. Bersani, D. Giubertoni, and V. Soncini, J. Appl. Phys. 94, 4950 (2003).

${ }^{13}$ M. Ferri, S. Solmi, A. Parisini, M. Bersani, D. Giubertoni, and M. Barozzi, J. Appl. Phys. 99, 113508 (2006).

${ }^{14}$ C. S. Rafferty, H.-H. Vuong, S. A. Eshraghi, M. D. Giles, M. R. Pinto, and S. J. Hillenius, Tech. Dig.-Int. Electron Devices Meet., 1993, p. 311.

${ }^{15}$ R. Kasnavi, Y. Sun, R. Mo, P. Panetta, P. B. Griffin, and J. D. Plummer, J. Appl. Phys. 87, 2255 (2000).

${ }^{16}$ M. Y. L. Jung, R. Gunawan, R. D. Braatz, and E. G. Seebauer, J. Appl. Phys. 95, 1134 (2004).

${ }^{17}$ O. I. Velichko, V. A. Dobrushkin, and V. A. Tsurko, in Interaction of Radiation with Solids, The 5th International Conference, Minsk, Belarus (2003).

${ }^{18}$ H. Park, K. S. Jones, J. A. Slinkman, and M. E. Law, Tech. Dig. Int. Electron Devices Meeting, 1993, p. 303.

${ }^{19}$ R. A. Camillo-Castillo, M. E. Law, and K. S. Jones, Mater. Sci. Eng., B 114-115, 312 (2004).

${ }^{20}$ J. A. Van den Berg, D. G. Armour, S. Zhang, S. Whelan, H. Ohono, T.-S. Wang, A. G. Cullis, E. J. H. Collart, R. D. Goldberg, P. Bailey, and T. C. Q. Noakes, J. Vac. Sci. Technol. B 20, 974 (2002).

${ }^{21}$ M. J. P. Hopstaken, Y. Tamminga, M. A. Verheijen, R. Duffy, V. C. Venezia, and A. Heringa, Appl. Surf. Sci. 231-232, 688 (2004).

${ }^{22}$ G. K. Celler and S. Cristoloveanu, J. Appl. Phys. 93, 4955 (2003).

${ }^{23}$ P. Fahey and S. Solmi, J. Appl. Phys. 60, 4329 (1986).

${ }^{24}$ K. L. Yeo, A. T. S. Wee, and Y. F. Chong, J. Appl. Phys. 96, 3692 (2004).

${ }^{25}$ J. J. Hamilton, E. J. H. Collart, B. Colombeau, M. Bersani, D. Giubertoni, J. A. Sharp, N. E. B. Cowern, and K. J. Kirkby, Mater. Sci. Eng., B 124-125, 215 (2005).

${ }^{26}$ J. J. Hamilton, N. E. B. Cowern, J. A. Sharp, K. J. Kirkby, E. J. H. Collart, B. Colombeau, M. Bersani, D. Giubertoni, and A. Parisini, Appl. Phys. Lett. 89, 042111 (2006).

${ }^{27}$ N. E. B. Cowern, G. F. A. van de Walle, P. C. Zalm, and D. J. Oostra, Phys. Rev. Lett. 69, 116 (1992).

${ }^{28}$ J. J. Hamilton, E. J. H. Collart, B. Colombeau, C. Jeynes, M. Bersani, D. Giubertoni, J. A. Sharp, N. E. B. Cowern, and K. J. Kirkby, Nucl. Instrum. Methods Phys. Res. B 237, 107 (2005).

${ }^{29}$ M. Bersani, D. Giubertoni, E. Iacob, M. Barozzi, S. Pederzoli, L. Vanzetti, and M. Anderle, Appl. Surf. Sci. 252, 7315 (2006).

${ }^{30}$ W. Vandervorst, T. Janssens, B. Brijs, T. Conard, C. Huyghebaert, J. Fruhauf, A. Bergmaier, G. Dollinger, T. Buyuklimanli, J. A. van den Berg, and K. Kimura, Appl. Surf. Sci. 231-232, 618 (2004).

${ }^{31}$ C. Bonafos, A. Claverie, D. Alquir, C. Bergaud, A. Martinez, L. Laânab, and D. Mathiot, Appl. Phys. Lett. 71, 365 (1997).

${ }^{32}$ A. Höfler, Th. Feudel, N. Strecker, W. Fichtner, K.-H. Stegemann, H. Syhre, and G. Dallmann, J. Appl. Phys. 78, 3671 (1995).

${ }^{33}$ J. J. Hamilton, E. J. H. Collart, M. Bersani, D. Giubertoni, M. Kah, N. E. B. Cowern, and K. J. Kirkby, Mater. Res. Soc. Symp. Proc. 912, C01-10 (2006).

${ }^{34}$ B. J. Pawlak, R. Surdeanu, B. Colombeau, A. J. Smith, N. E. B. Cowern, R. Lindsay, W. Vandervorst, B. Brijs, O. Richard, and F. Cristiano, Appl. Phys. Lett. 84, 2055 (2004).

${ }^{35}$ S. Solmi, in The 1st International Rapid Thermal Processing Conference (RTP'93), edited by R. B. Fair and B. Lojek (Scottsdate, Arizona, 1993), p. 179.

${ }^{36}$ S. Solmi, E. Landi, and F. Baruffali, J. Appl. Phys. 68, 3250 (1990). 